\title{
Reversible Coloring/Decoloring Reactions of Thermochromic Leuco Dyes Controlled by a Macrocyclic Compound Developer
}

\author{
Sanguansak Sriphalang \\ Chiang Mai University \\ Audchara Saenkham \\ Srinakharinwirot University \\ Tawatchai Chaodongbung \\ Mahasarakham University \\ Banchob Wanno \\ Mahasarakham University \\ chatthai kaewtong ( $\nabla$ kchatthai@gmail.com ) \\ Mahasarakham University \\ Datchanee Pattavarakorn \\ Chiang Mai University
}

\section{Research Article}

Keywords: Bis-phenol A (BPA), Macrocyclic Compound, Developer, Thermochromic dyes, Leuco dye

Posted Date: February 1st, 2022

DOI: https://doi.org/10.21203/rs.3.rs-1258180/v1

License: (1) This work is licensed under a Creative Commons Attribution 4.0 International License. Read Full License 


\section{Abstract}

In this study, we examine macrocyclic compounds to determine whether they can provide a safer replacement and stable complex for BPA in thermochromic dyes. To achieve this objective, a series of macrocyclic compounds, Methyl- $N$-benzylhexahomo-triazacalix[3]arene (MeAC3), $p$-Chloro- $N$ benzylhexahomo-triazacalix[3]arene (CIAC3), a-Cyclodexdrin (a-CD), $\beta$-Cyclodexdrin ( $\beta$-CD). $p$-tertButylthiacalix[4]arene (TC4), Calix[4]arene (C4) and Resorcin[4]arene (RC4) were synthesized. Among these macrocyclic compounds, RC4 was determined to be the most appropriate candidate to replace BPA as the developer material used in thermochromic dyes. In tests of prepared thermochromic dyes, RC4 had results similar to those of BPA, achieving the best protonation/deprotonation equilibria and providing a dark contrast with the thermochromic dye. DFT calculations also showed stable complexes between RC4 and CVL via hydrogen-bond interactions.

\section{Introduction}

Thermochromic (temperature sensitive) dyes (TC) are materials which change color as a function of temperature [1]. They can be used in several different applications such as sensors, thermal indicators, memory storage devices, security inks, and dyes for solar cells and other luminescent switches of solidstate materials [2-5]. Normally, leuco dye-based TC composites have three components, including a color former (leuco dye), a color developer and a solvent. The color changes in this system result from two competing reactions, one between the dye and the developer and the other between the solvent and the developer. Common color formers, such as spirolactone, fluoranes, spiropyrans or fulgides, are electrondonating compounds [6]. One of the various types of color formers, crystal violet lactone (CVL), is a classic halochromic dye which has been widely used as a chromogenic reagent in thermochromic systems [7]. Bis-phenol A (BPA) has been intensively used as a color developer because of its efficiency and low cost [8]. However, previous research has shown that BPA exposure can potentially cause various detrimental health effects such as heart disease, breast cancer, infertility, and neuro-developmental disorders [10]. Skin penetration/absorption of BPA for someone simply holding thermal printing papers can reach $71 \mathrm{mg} /$ day [9]. In addition, the absence of stability of a complex system (three components) is also a problem in leuco dye applications. Therefore, many researchers are interested in finding new substrates to serve as suitable color developers. Recently, linear-type and hyperbranched-type polyphenol derivatives have been used as developer materials for temperature sensitive dyes [11, 12]. However, it was found that this type of polymer has a few disadvantages such as poor molecular weight control, high polydispersities, and low blocking efficiencies [13]. The results of these studies have been difficult to interpret, and analysts have reached different conclusions about its use as color developer. Macrocyclic compounds are known as traditional supramolecules based on the specific channel where molecular recognition is possible. Normally, their structure, composed of phenol units and alcohol groups, can be used as a novel developer material. To the best of our knowledge, there have not been any studies about using this type of developer material for temperature sensitive dyes. In this work, we study various 
macrocyclic compounds. (MeAC3, ClAC3, TC4, C4, $\mathbf{a - C D}, \boldsymbol{\beta}-\mathrm{CD}$ and RC4) as color developers, as they have good stability, exact molecular weights and good complexation properties.

\section{Materials And Methods}

\subsection{Reagents and Chemicals}

All reagents were analytical grade. $\beta$-Cyclodexdrin was purchased from Acros Organics. $a$-Cyclodexdrin, $p$ chlorophenol, $p$-tert-butylphenol and $p$-cresol were purchased from Fluka. Crystal violet lactone (CVL), 1octadecanol (OD), resorcinol, formaldehyde $40 \% \mathrm{w} / \mathrm{v}$ and sodium hydroxide $(\mathrm{NaOH})$ were purchased from Carlo Erba Reagents. Hydrochloric acid 37\% $(\mathrm{HCl})$ was purchased from Anapure. Tetrahydrofuran (THF, Sigma-Aldrich) was distilled over sodium and benzophenone was distilled under a nitrogen atmosphere. Commercial grade solvents including acetone, hexane, dichloromethane, methanol, and ethyl acetate were distilled before use. Toluene (Labscan) and dimethyl formamide (DMF, Labscan) were dried over $\mathrm{CaH}_{2}$ and freshly distilled under a nitrogen atmosphere prior to use.

\subsection{Instrumentation and Apparatus}

${ }^{1} \mathrm{H}-\mathrm{NMR}$ spectra were measured using a Varian $400 \mathrm{MHz}$ spectrometer in $\mathrm{CDCl}_{3}$ with $\mathrm{TMS}$ as an internal reference. Fluorescence spectra in solution were measured with a Perkin Elmer LS 50B spectrometer. Absorbance spectra were recorded with a Perkin Elmer Lambda 25 UV-Vis spectrometer. FT-IR spectra were recorded with a Bruker Tensor 27 FT-IR spectrometer. SEM measurements were performed with a Zeiss (LEO) 1450VP microscope. A Thermogravimetric analysis (TGA) was carried out using a SDT Q600 from TA Instruments.

\subsection{Synthesis of $p$-Chloro- $N$ - benzylhexahomotriazacalix[3]arene (CIAC3)}

CIAC3 was synthesized according to a methodology modified from the literature [14]. 4-Chloro-2,6bis(hydroxymethyl) phenol $(6.00 \mathrm{~g}, 32.52 \mathrm{mmol})$ and benzylamine $(3.39 \mathrm{~g}, 31.67 \mathrm{mmol})$ were dissolved in $150 \mathrm{~mL}$ of xylene and the resulting mixture was refluxed for $72 \mathrm{~h}$. During the course of the reaction, generated water was removed with a Dean-Sturk condenser. The mixture was evaporated to dryness, creating a deep yellow oil. on a silica gel (hexane:EtOAc) 9:1, v/v) $\left(2.73 \mathrm{~g}, 33 \%\right.$ yield) were as follows: ${ }^{1} \mathrm{H}$ NMR (400 MHz, CDCl ${ }_{3}$ ): $\delta 7.29$ (br s, g 15H, ArH), 7.01 (s, 6H, ArH), 3.69 (s, 6H, NCH $\left.\mathrm{Ar}_{2}\right), 3.64(\mathrm{~s}, 12 \mathrm{H}$, $\mathrm{NCH}_{2} \mathrm{Ar}$ ). FTIR (KBr). v 3054, 3023, 2832, 2805, 1738, 1602, 1470, 1372, 1240, 1116, 863, 738, 699, 485 $\mathrm{cm}^{-1}$.

\subsection{Synthesis of p-Methyl-N- benzylhexahomotriazacalix[3]arene (MeAC3)}

Undergoing a process similar to that described for CIAC3 above, 4-Methyl-2,6-bis(hydroxymethyl)phenol $(5.47 \mathrm{~g}, 32.52 \mathrm{mmol})$ and benzylamine $(3.39 \mathrm{~g}, 31.67 \mathrm{mmol})$ was added to $150 \mathrm{~mL}$ of xylene. The 
resulting mixture was refluxed for $72 \mathrm{~h}$, with generated water removed with a Dean-Sturk condenser during the course of the reaction. The mixture was evaporated to dryness, creating a deep yellow oil. The results of chromatography performed on a silica gel (hexane:EtOAc) 9:1, v/v) (3.50 g, 45\% yield) were as follows: ${ }^{1} \mathrm{H}$ NMR (400 MHz, $\mathrm{CDCl}_{3}$ ): $\delta 11.22$ (br s, g 3H, OH), 7.22 (br s, g 15H, ArH), 7.03 (s, 6H, ArH), 3.64 (s, 6H, NCH $2 \mathrm{Ar}$ ), 3.56 (s, 12H, NCH

\subsection{Synthesis of p-tert-Butylthiacalix[4]arene (TC4)}

TC4 was synthesized in a manner similar to that described in the literature with a slight adjustment [15]. A solution of $p$-tert-butylphenol $(64.5 \mathrm{~g}, 0.43 \mathrm{~mol})$, elemental sulfur $\mathrm{S}_{8}(27.5 \mathrm{~g}, 0.86 \mathrm{~mol})$, and $\mathrm{NaOH}(8.86$ $\mathrm{g}, 0.215 \mathrm{~mol})$ in tetraethylene glycol dimethyl ether $(19 \mathrm{~mL})$ was stirred under nitrogen. The stirred mixture was gradually heated to $230^{\circ} \mathrm{C}$ over a period of $4 \mathrm{~h}$ and kept at this temperature for a further $3 \mathrm{~h}$ with concomitant removal of the evolving hydrogen sulfide by using a slow stream of nitrogen gas. The resulting dark red product was cooled to an ambient temperature and diluted with toluene and ether mixture. Then $0.5 \mathrm{M}$ aq. sulfuric acid was added to the solution using vigorous stirring to get a suspension. The precipitate was collected by filtration, recrystallized with chloroform and dried in vacuo $\left(100^{\circ} \mathrm{C}, 4 \mathrm{hr}\right)$ to obtain an essentially pure sample of TC4 $(28.53 \mathrm{~g}, 36.7 \%)$. This resulted in ${ }^{1} \mathrm{H}$ NMR (400 $\left.\mathrm{MHz}, \mathrm{CDCl}_{3}\right): \delta 9.56(\mathrm{~s}, 4 \mathrm{H}, \mathrm{OH}), 7.52(\mathrm{~s}, 8 \mathrm{H}, \mathrm{ArH})$, and $1.33\left(\mathrm{~s}, 36 \mathrm{H}, \mathrm{t}-\mathrm{C}_{4} \mathrm{H}_{9}\right)$.

\subsection{Synthesis of Calix[4]arene (C4)}

C4 was synthesized using a process slightly modified from the literature [16]. A solution of $p$-tertbutylphenol $(51.81 \mathrm{~g}, 0.38 \mathrm{~mol}), 37 \%$ formaldehyde solution $(34 \mathrm{~mL}, 0.42 \mathrm{~mol})$ and sodium hydroxide $(1.00 \mathrm{~g}, 0.025 \mathrm{~mol})$ was stirred in an open flask and heated in a silicone bath for $c a .2 \mathrm{~h}$ at $110-120^{\circ} \mathrm{C}$. The reaction mixture was allowed to cool to room temperature and diphenyl ether $(900 \mathrm{~mL})$ was then added to the flask. The mixture was transferred to a 1-L one-necked round bottom flask, then the reaction mixture was refluxed under nitrogen for 1.5-2 $\mathrm{h}$ until no water vapor remained and cooled to room temperature. Ethyl acetate $300 \mathrm{~mL}$ was then added to precipitate the product. After the (p-tertButylthiacalix[4]arene, TC4) precipitate was filtered and dried, it yielded: $28.40 \mathrm{~g}, 47.1 \%$. ${ }^{1} \mathrm{H}$ NMR (400 $\mathrm{MHz}, \mathrm{CDCl}_{3}$ ): $\delta$ 10.37s, 4H, $\left.\operatorname{ArOH}\right), 7.10$ (s, 8H, $\left.m-\mathrm{ArH}\right), 4.32$ (d, $\left.J=14 \mathrm{~Hz}, 4 \mathrm{H}_{\mathrm{A}}, \operatorname{ArCH}_{2} \mathrm{Ar}\right), 3.53$ (d, $J=13.2$ $\left.\mathrm{Hz}, 4 \mathrm{H}_{\mathrm{B}}, \mathrm{ArCH} \mathrm{H}_{2} \mathrm{Ar}\right)$, and $1.28\left(\mathrm{~s}, 36 \mathrm{H}, \mathrm{t}-\mathrm{C}_{4} \mathrm{H}_{9}\right)$.

Then, a solution of $p$-tert-butylcalix[4]arene, TC4 $(9.88 \mathrm{~g}, 15.20 \mathrm{mmol})$, aluminium chloride $(9.85 \mathrm{~g}, 73.80$ $\mathrm{mmol})$, phenol $(6.95 \mathrm{~g}, 73.80 \mathrm{mmol})$ and toluene $(50 \mathrm{~mL})$ was stirred under a nitrogen atmosphere at room temperature for $1 \mathrm{~h}$. The reaction mixture was poured into $100 \mathrm{~mL}$ of $3 \mathrm{M}$ hydrochloric and stirred for 10 mins, then extracted with dichloromethane. The organic layer was dried over anhydrous sodium sulfate, filtered, and concentrated under reduced pressure. Methanol was subsequently added to precipitate a white powder $\mathrm{C4}(4.23 \mathrm{~g}, 64.5 \%)$, resulting in ${ }^{1} \mathrm{H} \mathrm{NMR}\left(400 \mathrm{MHz}, \mathrm{CDCl}_{3}\right): \delta 10.29(\mathrm{~s}, 4 \mathrm{H}$, $\operatorname{ArOH}), 7.12(\mathrm{~d}, J=8 \mathrm{~Hz}, 8 \mathrm{H}, m-\operatorname{Ar} H), 6.82(\mathrm{t}, J=8 \mathrm{~Hz}, 4 \mathrm{H}, p-\operatorname{Ar} H), 4.27\left(\mathrm{AB}, 4 \mathrm{H}_{\mathrm{A}}, \mathrm{ArCH}_{2} \mathrm{Ar}\right)$, and 3.54 (AB, $4 \mathrm{H}_{\mathrm{B}}, \mathrm{ArCH} \mathrm{Hr}_{2} \mathrm{Ar}$.

\subsection{Synthesis of resorcin[4]arene (RC4)}


A methodology found in the literature was modified to synthesize RC4 [17]. Formaldehyde (4.075 g, 0.1 mol) was immediately added to a solution of resorcinol $(14.95 \mathrm{~g}, 0.1 \mathrm{~mol})$ in $\mathrm{H}_{2} \mathrm{O}(680 \mathrm{~mL})$ and $\mathrm{NaOH}$ $(10.86 \mathrm{~g}, 0.2 \mathrm{~mol})$ at $0^{\circ} \mathrm{C}$. The mixture was maintained at $0^{\circ} \mathrm{C}$ for $2 \mathrm{~h}$ with efficient stirring under $\mathrm{N}_{2}$. After $24 \mathrm{~h}$ standing at room temperature, the dark mixture was cooled again to $0^{\circ} \mathrm{C}$ before being neutralized with $\mathrm{HCl}(0.2 \mathrm{~mol})$. The brown precipitate that separated from the aq. medium was filtered, washed with $\mathrm{H}_{2} \mathrm{O}$ to eliminate $\mathrm{HCl}$ and $\mathrm{NaCl}$, and dried. The reddish solid was covered with $\mathrm{MeOH}(100 \mathrm{~mL})$ and stirred for $2 \mathrm{~h}$ to dissolve any impurities. The insoluble material (RC4) was filtrated and dried [3], resulting in ${ }^{1} \mathrm{H}$ $\operatorname{NMR}\left(400 \mathrm{MHz}, \mathrm{CDCl}_{3}\right)$ : $\delta 9.65$ and $9.24(\mathrm{~s}, 4 \mathrm{H}, \mathrm{ArOH}), 7.20$ and $6.12(\mathrm{~s}, 4 \mathrm{H}, \mathrm{ArH}), 4.17(\mathrm{t}, 4 \mathrm{H}, \mathrm{Ar} H), 2.20$ and $1.28\left(8 \mathrm{H}, \mathrm{CH}_{2}\right)$. FTIR $(\mathrm{KBr}): \mathrm{v}=3460 \mathrm{~cm}^{-1}(-\mathrm{OH}), 1430 \mathrm{~cm}^{-1}(\mathrm{C}-\mathrm{C})$ and $1280 \mathrm{~cm}^{-1}\left(-\mathrm{CH}_{2}\right)$.

\subsection{Preparation of leuco dyes (LD1-LD7)}

Leuco dyes containing CVL, macrocyclic compounds, and OD were prepared using the following procedure. First, CVL, macrocyclic compounds, and OD in a ratio of 1 (CVL), 6 (macrocyclic compounds) and 100 (OD) were added to a flask with a tight-fitting lid [18]. After the mixture had been heated at $160^{\circ} \mathrm{C}$ for $30 \mathrm{~s}$, the white 1-octadecanol solid in the prepared samples completely melted into a transparent liquid. The samples returned to their solid forms when cooled to room temperature. The Leuco dye compounds obtained were pale-yellow, white, and blue solids. The macrocyclic compounds used for preparing leuco dyes were composed as follows:

Leuco dye 1 (LD1); CVL 0.10 g, 0.24 mmol: MeAC3 1.03 g, 1.44 mmol: OD 4.48 g, 24 mmol

Leuco dye 2 (LD2); CVL $0.10 \mathrm{~g}, 0.24$ mmol: ClAC3 $1.12 \mathrm{~g}, 1.44$ mmol: OD 4.48 g, 24 mmol

Leuco dye 3 (LD3); CVL 0.10 g, 0.24 mmol: TC4 1.04 g, 1.44 mmol: OD 4.48 g, 24 mmol

Leuco dye 4 (LD4); CVL 0.10 g, 0.24 mmol: C4 0.61 g, 1.44 mmol: OD 4.48 g, 24 mmol

Leuco dye 5 (LD5); CVL 0.10 g, 0.24 mmol: a-CD 1.47 g, 1.44 mmol: OD 4.48 g, 24 mmol

Leuco dye 6 (LD6); CVL 0.10 g, 0.24 mmol: $\beta$-CD 1.63 g, 1.44 mmol: OD 4.48 g, 24 mmol

Leuco dye 7 (LD7); CVL $0.10 \mathrm{~g}, 0.24$ mmol: RC4 $0.70 \mathrm{~g}, 1.44 \mathrm{mmol}$ : OD $4.48 \mathrm{~g}, 24 \mathrm{mmol}$

\subsection{Study of color differences in leuco dyes}

Leuco dyes were heated from 30 to $80^{\circ} \mathrm{C}$, and color changes were recorded. A larger value of $L^{*}$ (lightness) indicates that the surface of the measured object was light and a smaller value indicates that it was dark. Red-green color changes are represented by $a^{*}$, with positive values indicating red and negative values signifying green. Yellow-blue color changes are shown by $b^{*}$, with positive values denoting that the surface of the object measured was yellow, and negative $b^{*}$ values indicating blue. The symbol $C *$ indicates color chroma and $h *$ indicates hue. Thus, color differences were calculated using the following formula: 
$\Delta \mathrm{E}^{\star}=\left[\left(\Delta \mathrm{L}^{\star}\right)^{2}+\left(\Delta \mathrm{a}^{\star}\right)^{2}+\left(\Delta \mathrm{b}^{\star}\right)^{2}\right]^{1 / 2}$

Where: $\Delta \mathrm{L}^{*}$ (brightness difference $)=\mathrm{L} 1^{*}-\mathrm{L} 2^{*}, \Delta \mathrm{a}^{*}$ (red and green difference $)=\mathrm{a} 1^{*}$-a $2^{*}$, and $\Delta \mathrm{b}^{*}$ (yellow blue difference $)=b 1^{*}-b 2^{\star}$. $L 1^{*}, a 1^{*}$ and $b 1^{*}$ are all initial values $\left(30^{\circ} \mathrm{C}\right)$, while $L 2^{*}, a 2^{*}$ and $b 2^{*}$ are the values after the temperature change [19].

\section{Results And Discussion}

\subsection{Macrocyclic compounds}

All macrocyclic compounds were prepared using a condensation reaction slightly adapted from the literature [14-17]. The chemical structures of macrocyclic compounds were characterized by ATR-FTIR, ${ }^{1} \mathrm{H}-\mathrm{NMR}$ and mass measurements. As shown in Fig. 1, their structures are typically composed of phenol unit and alcohol groups. These can be used as color developers by acting as proton donors, changing the dye molecule between its leuco and protonated colored forms.

\subsection{Leuco dye formation and properties}

In order to investigate the color-forming abilities of synthesized macrocyclic compounds, mixtures of macrocyclic compounds CVL and OD in a ratio 1 (CVL) : 6 (macrocyclic compounds) : 100 (OD) were prepared. The mixture was then heated on a hot plate at $160^{\circ} \mathrm{C}$ for $30 \mathrm{~s}$ until completely melted (molten mixture). All samples were brought back to solid form by cooling them to room temperature. Fig. 2 shows photographs of the leuco dyes LD1-LD7 before and after heat treatment. It was found that only LD7 exhibited a blue to black color change when taken from room temperature to $160^{\circ} \mathrm{C}$. A color change in LD7 upon heating $\left(160^{\circ} \mathrm{C}\right)$ indicated that in the presence of RC4, CVL dyes underwent a structural change. They transformed from a closed-lactone form to an open-lactone form when heated due to the release of protons from developer materials, and thus turned black [11]. In addition, this colored/decolored reaction was reversible for more than several cycles. On the other hand, no CVL chemical, structural or color changes occurred in other leuco dyes (LD1-LD6).

The opening of lactone rings in CVL dyes in LD7 was confirmed using ATR-FTIR measurements. The spectra of LD7 and pure compounds are shown in Fig. 3. Pure CVL exhibited C-C stretching in the aromatic ring at 1611 and $1440 \mathrm{~cm}^{-1}$. A strong peak appearing at $1070 \mathrm{~cm}^{-1}$ was attributed to $\mathrm{C}-0$ stretching. The O-H stretching of RC4 appeared at $3316 \mathrm{~cm}^{-1}$. Peaks at 2933 and $2859 \mathrm{~cm}^{-1}$ belonged to the $-\mathrm{CH}_{2}$ asymmetric stretching vibration of an aliphatic chain. In the spectra of LD7, a sharp lactone stretching band $(C=0)$ near $1740 \mathrm{~cm}^{-1}$ of LD7 clearly decreased and slightly shifted to $1755 \mathrm{~cm}^{-1}$ after heating because of a ring opening caused by protonation of the lactone structure of CVL dyes [20]. The color-forming reaction tests in LD7 confirms that RC4 is capable of complexation forming and opening the lactone ring of Leuco dyes by releasing protons from phenolic groups.

Additionally, the thermal stability of macrocyclic compounds and leuco dyes (LD1-LD7) were studied using the TGA method. The TGA thermogram in Fig. 4a shows that the initial temperature causing a 10\% 
weight loss in all macrocyclic compounds was above $250^{\circ} \mathrm{C}$. In the cases of CIAC3 and RC4, the TGA indicates that under normal atmospheric conditions, the macrocyclic compounds transformed into thermal-resistant residuals such as polymer [21]. Fig. 4b shows that LD1-LD7 had a 10\% loss weight at $240^{\circ} \mathrm{C}$, and just $20 \%$ of the original sample weight remained at $800^{\circ} \mathrm{C}$. A TGA curve of LD7 shows an increasing in percentage of weight loss (in which \%residue decreased from 42-19\%) which might be explained by complexation between RC4 and CVL leading to a decrease in thermal-resistant residual species.

The morphology and particle size distribution of the microcapsules were determined by means of SEM photographs. Fig. 5 shows the microstructure of leuco dye pigments using BPA and RC4 as color developers. Fig. $5 \mathrm{a}$ and $5 \mathrm{~b}$ are SEM images of leuco pigments which have average diameters of 0.3-0.6 $\mu \mathrm{m}$ and were developed with BPA. Fig. $5 c$ and $5 d$ are SEM images of leuco pigments which have average diameters of 2.8-3.5 $\mu \mathrm{m}$ and were developed with RC4. The SEM micrograph of RC4 shows an increase in crystallinity and particle size when compared to conventional BPA developers. These results might be attributed to $\pi-\pi$ interactions and hydrogen bonding of RC4 and CVL in leuco dyes [22].

\subsection{Computational study}

To further study the properties of CVL, RC4 and LD7, optimized geometries and HOMO and LUMO energies were computed using density functional theory (DFT) calculations at a B3LYP/LanL2DZ theoretical level through the Gaussian 09 program [23]. The lowest energy structures of CVL RC4 and LD7 are shown in Fig. 6. It is clearly seen that the molecular geometries of CVL and RC4 found in LD7 distorted from their free forms and intermolecular hydrogen bonds $(\mathrm{OH} \cdots \mathrm{O})$ appeared in the complex. The $\mathrm{OH} \cdots \mathrm{O}$ hydrogen bond distance was found to be $1.78 \AA$. In addition, the calculated energies of LD7 (-3005.7 a.u.) were lower than those of both CVL (-1322.7 a.u.) and RC4 (-1683.0 a.u.). As demonstrated in the optimized structures, it was found that RC4 could form stable complexes with CVL using complexation, as shown in Fig. 6.

The electron distributions and orbital energies of the HOMO and LUMO of CVL (lactone form), and RC4 and LD7 (OD, RC4, $\mathrm{CVL}^{+}$(cationic form)) are presented in Fig. 7. In the cases of CVL and $\mathrm{CVL}^{+}$, the $\mathrm{HOMO}$ were all localized on a phenyl unit. However, the LUMO were localized on lactone units in CVL and uniformly distributed throughout the entire molecule in $\mathrm{CVL}^{+}$, suggesting that cationic forms are more extensively delocalized than lactone forms. Furthermore, both HOMO and LUMO of RC4 and CVL ${ }^{+}$in LD7 are different from those of free molecules. The HOMO levels of CVL, RC4 and LD7 have energy values of $-0.181,-0.206$, and $-0.182 \mathrm{eV}$, respectively. The LUMO levels of CVL, RC4 and LD7 have energy values of $-0.040,-0.026$, and $-0.061 \mathrm{eV}$, respectively. The results indicate that the energy band gap of LD7 $(0.121 \mathrm{eV})$ is considerably smaller than that of CVL $(0.141 \mathrm{eV})$ and RC4 $(0.180 \mathrm{eV})$, and the cationic form in LD7 is more delocalized than the lactone form in CVL owing to the hydrogen-bond interactions of the color former-developer [24].

\subsection{Color differences in Leuco dyes}


Digital photography was used to evaluate the effect of temperature changes on color. The methodology used a bulk molten mixture of LD7 in vials, tempered in a water bath. After reaching desired temperature, the samples were removed from the water bath and an image was recorded using a digital camera. Then, images were transformed into trichromatic values $\mathrm{XYZ}$, with consequent calculations of visual color differences. The trend of LD7 color difference variations based on temperature changes from $30-80^{\circ} \mathrm{C}$ is shown in Fig. 8. The color of LD7 changed from blue to black as the temperature increased. When the molten mixture of LD7 was heated to $60^{\circ} \mathrm{C}$, the color changed significantly. The color of LD7 began to change around $60^{\circ} \mathrm{C}$.

\section{Conclusion}

We report on a series of macrocyclic compounds (MeAC3, CIAC3, TC4, C4, $\boldsymbol{\alpha}-\mathrm{CD}, \boldsymbol{\beta}-\mathrm{CD}$ and RC4) which were prepared to investigate their feasibility as developer materials for temperature sensitive dyes. After analyzing various macrocyclics, RC4 is found to be the most appropriate candidate for a novel color developer in temperature sensitive dye thermal papers based on its coloring/decoloring reactions. It is found that RC4 has a high static sensitivity and a dark contrast of leuco dye, similar to that found in BPA. This first successful demonstration of the use of macrocyclic compounds as developer materials for temperature sensitive dyes opens up a new pathway for the development of macrocyclic compounds as replacements for problematic BPA developer materials.

\section{Declarations}

\section{Funding}

This research project was financially supported by Mahasarakham University 2021 and Center of Excellence for Innovation in Chemistry (PERCH-CIC), Office of the Higher Education Commission, Ministry of Education. This research work also was partially supported by Chiang Mai University and the Graduate School, Chiang Mai University.

Conflicts of interest/Competing interests The authors declare no conflicts of interest/competing interests.

Availability of data and material Not applicable (All data generated or analyzed during this study are included in this published article).

Code availability Not applicable.

Authors' contributions S. Sriphalang, C. Kaewtong and D. Pattavarakorn contributed to the study conception and design. The DFT calculations were performed by S. Sriphalang and B. Wanno. The experimental procedures were performed by S. Sriphalang, A. Saenkham, T. Chaodongbung, C. Kaewtong and D. Pattavarakorn. The data analysis and the first draft of the manuscript were made by C. Kaewtong, D. Pattavarakorn, and B. Wanno. Revising the manuscript critically for important intellectual content on 
subsequent versions of the manuscript has done by S. Sriphalang, A. Saenkham, T. Chaodongbung, C. Kaewtong and D. Pattavarakorn All the authors read and approved the final manuscript.

Declarations The authors declare that they have no known competing financial interests or personal relationships that could have appeared to influence the work reported in this paper.

\section{References}

1. (a)White MA, Bourque AColorant, Thermochromic.In:Luo MR(eds)Encyclopedia of Color Science and Technology.Springer, York N, Seeboth A, Lötzsch D, Ruhmann R, Muehling O (2016) Thermochromic Polymers-Function by Design.Chem. Rev.2014, 114(5), 3037-3068.(c)Zhang, W.; Ji, X.; Zeng, C.; Yin, Y.; Wang, C.(2019), A sultone-based reversible dark red-yellow conversion thermochromic colorant with adjustable switching temperature.Coloration Technol, 2019, 135, 97-102

2. Hagfeldt A, Boschloo G, Sun L, Kloo L, Pettersson H, Manuel PC, Alejandro LF, Juan MH, Alfonso SC, del María CP, Silvia TP, Enrique C (eds) (2010) Chem. Rev. 110(11), 6595-6663.(b)Manuel PC, Alejandro LF, Juan MH, Alfonso SC, María del CP, Silvia TP, Enrique C, Luis Fermín C.V..Thermochromic sensor design based on Fe(II)spin crossover/polymershybrid materials and artificial neural networks as a tool in modelling.Sens. Actuators B Chem.2015, 208, 180-187

3. Beija M, Afonso CAM, Martinho JMG (2009) Synthesis and applications of Rhodamine derivatives as fluorescent probes. Chem 38(8):2410-2433.

4. Mishra A, Fischer MKR, Bäuerle P (2009) Metal-Free Organic Dyes for Dye-Sensitized Solar Cells: From Structure: Property Relationships to Design Rules. Angew 48(14):2474-2499.

5. Zhu CF, Wu AB (2005) Studies on the synthesis and thermochromic properties of crystal violet lactone and its reversible thermochromic complexes. Thermochim 425:7-12

6. Kulčar R, Friškovec M, Hauptman N, Vesel A, Gunde MK, Song Z, Liu R, Zhu H, Lu Y, Li X, Zhu H (eds) (2010) Dyes Pigm. 86(3), 271-277.(b)Song Z, Liu R, Zhu H, Lu Y, Li X, Zhu H.Smart inks based onAIPE-active heteroleptic Ir(III)complexes. Sens. Actuators B Chem.2019, 279, 385-392

7. Panák O, Držková M, Kaplanová M (2015) Insight into the evaluation of color changes of leuco dye based thermochromic systems as a function of temperature. Dyes Pigm 120:279-287

8. Muthyala R, Diamond AS, Weiss DS (eds) (1997) 2001

9. Biedermann S, Tschudin P, Grob K (2010) Transfer of bisphenol A from thermal printer paper to the skin. Anal 398(1):571-576.

10. (a)Alexander HC, Dill DC, Smith LW, Guiney PD, Dorn PBisphenol a:Acute aquatic toxicity. Environ. Toxicol. Chem. 7(1), 19-26.(b)Chen M-Y, Ike M, Fujita M, Hauser R, Marcus M (1988) Acute toxicity, mutagenicity, and estrogenicity of bisphenol-A and other bisphenols. Environ. Toxicol.2002, 17(1), 80-86.(c)Stump, D. G.; Beck, E. M. J.; Radovsky A.; Garman R. H.; Freshwater L. L.; Sheets L. TP.; Marty M. S.; Waechter J. M.; Dimond S. S.; Van Miller J. P.; Shiotsuka R. N.; Beyer D.;Chappelle A. H.; Hentges, S. G.Developmental neurotoxicity study of dietary bisphenol A in Sprague-Dawley rats. Toxicol Sci.2010, 115, 167-182.(d)Vandenberg, L.N.; Chahoud, I.; CHeindel, J.J.; Padmanabhan, V.; 
Paumgartten, F.J.; Schoenfelder, G.Urinary, Circulating, and Tissue Biomonitoring Studies Indicate Widespread Exposure to Bisphenol A. Environ. Health C Perspect.2010, 118, 1055-1070,

(e)Vandenberg, L.N.; Maffini, M.V.; Sonnenschein, A. C.; Rubin, B.S.; Soto, A.M.A Review of Controversies in the Field of Endocrine Disruption. Endocr. Rev.2009, 30, 75-95.(f)andenberg,L.N.; Hauser R, Marcus M; Olea, N.; Welshons, W.V.Human exposure to bisphenol A (BPA). Reprod. Toxicol.2007, 24, 139-177

11. Choi K-H, Kwon H-J, An B-K (eds) (2018) Eng. Chem. Res. 57(2), 540-547

12. Jang Y-I, Choi W-H, An B-K, Jang Y-I, An (eds) (2013) Korean Chem. Soc. 34, 1225-1231.(b)Jang Y-I, An, B.-K.Hyperbranched polyester copolymers for thermal printing papers:The effects of alkyl chain units in the polymer backbone on developing capability.Polymer.2015, 78, 193-201

13. Seal S (ed) (2007) Functional Nanostructures, Processing, Characterization and Applications. Springer

14. Kaewtong C, Jiang G, Park Y, Fulghum T, Baba A, Pulpoka B, Advincula R (2008) Azacalix[3]areneCarbazole Conjugated Polymer Network Ultrathin Films for Specific Cation Sensing. Chem 20(15):4915-4924

15. Kumagai H, Hasegawa M, Miyanari S, Sugawa Y, Sato Y, Hori T, Miyano S (1997) Facile synthesis of p-tert-butylthiacalix[4]arene by the reaction of p-tert-butylphenol with elemental sulfur in the presence of a base. Tetrahedron Lett 38(22):3971-3972

16. Morakot N, Tomapatanaget B, Ngeon-Tae W, Aeungmaitrepirom W, Tuntulani T (2005) Synthesis and Fluorescence Sensing Properties of Calix[4]arenes Containing Fluorophores. Supramol Chem 17(8):655-659

17. Bourgeois J-M, Stoeckli-Evans H (2005) Synthesis of New Resorcinarenes Under Alkaline Conditions. Helv 88(10):2722-2730.

18. Ogasawara K, Nakamura K, Kobayashi N (2016) Thermally controlled dual-mode display media with red-green-blue coloration and fluorescence via energy transfer between emission materials and leuco dyes.J. Mater. Chem. C. 4(21), 4805-4813

19. Yan X, Chang Y, Qian X (2019) Effect of the Concentration of Pigment Slurry on the Film Performances of Waterborne Wood Coatings. Coatings 9(10):635

20. Panák O, Držková M, Kaplanová M, Novak U, Klanjšek Gunde M (2017) The relation between colour and structural changes in thermochromic systems comprising crystal violet lactone, bisphenol $A$, and tetradecanol. Dyes Pigm 136:382-389

21. Zhao R, Xu H, Zhong Z, Xu H, Zhang H (2020) Hydrophobic and heat-resistant poly(methylphenylsiloxane)-modified resorcinol-formaldehyde composite xerogel monoliths and the carbonized derivatives. J Sol-Gel Sci 94:393-405

22. Chansri P, Wanno B, Keawwangchai S, Tuntulani T, Pulpoka B, Kaewtong C, Kaewtong C, Kampaengsri S, Singhana B, Pulpoka B (eds) (2019) Appl. Polym. Sci. 48273.(b)Kaewtong C, Kampaengsri S, Singhana B, Pulpoka BHighly selective detection of $\mathrm{Au}^{3+}$ using rhodamine-based modified polyacrylic acid(PAA)-coated ITO.Dyes Pigm.2017, 141, 277-285 
23. Fati Y, Aykut D, Pınar TT, Fikret K (2021) 137(4):336-347.(b)Frisch, M.J.; Trucks, G.W.; Schlegel, H. B..GAUSSIAN 09,Revision A.02.Wallingford(CT):Gaussian Inc; 2009

24. Zhang W, Ji X, Zeng C, Chen K, Yina Y, Wang C (2017) A new approach for the preparation of durable and reversible color changing polyester fabrics using thermochromic leuco dye-loaded silica nanocapsules. J 5:8169-8178.

Figures 


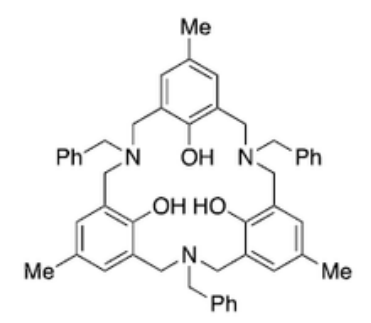

$p$-Methyl- $N$-benzylhexahomo-

triazacalix[3] arene (MeAC3)

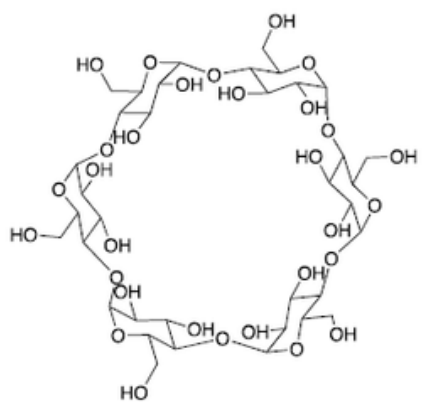

$\alpha$-Cyclodexdrin ( $\alpha$-CD)

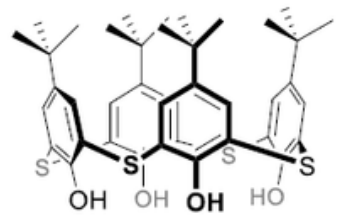

p-tert-Butylthiacalix[4]arene (TC4)

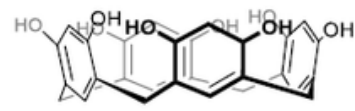

Resorcin[4]arene (RC4)

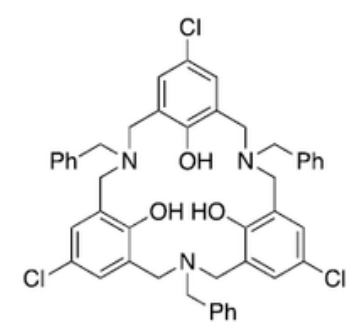

p-Chloro- $N$-benzylhexahomo-

triazacalix[3]arene (ClAC3)

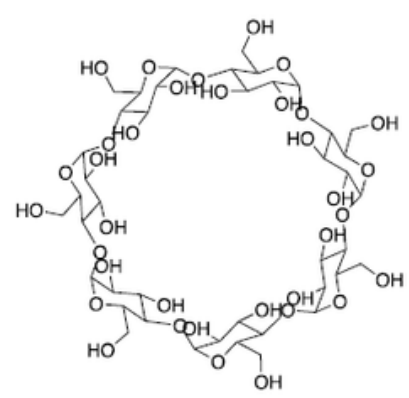

$\beta$-Cyclodexdrin $(\boldsymbol{\beta}$-CD)

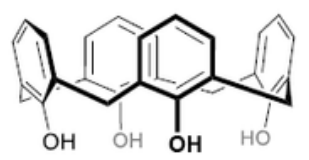

Calix[4]arene (C4)

\section{Figure 1}

Structure of macrocyclic compounds synthesized via a condensation reaction. 


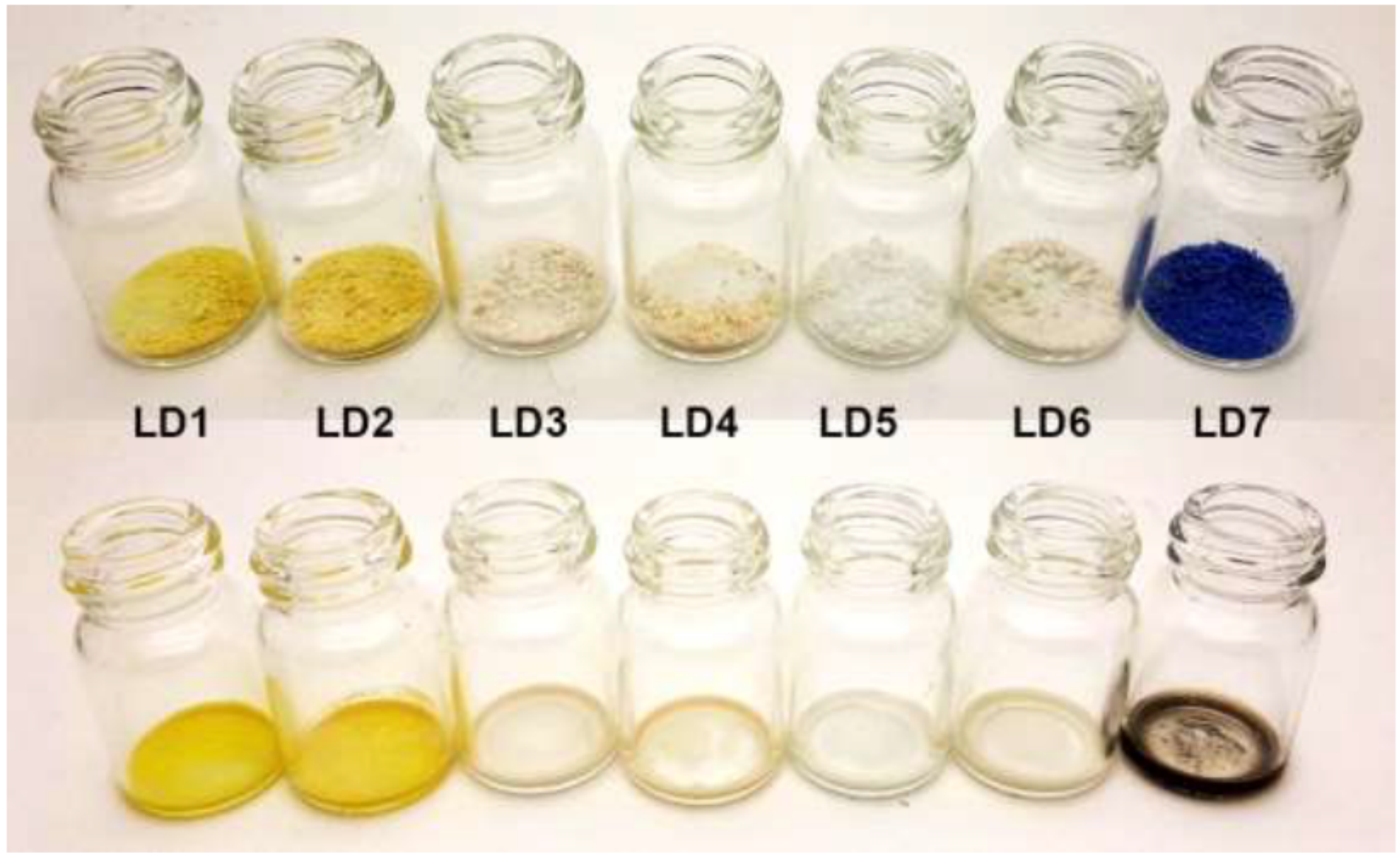

Figure 2

Photographs of LD1-LD7 before (up) and after (down) heat treatment at $160^{\circ} \mathrm{C}$ for $30 \mathrm{~s}$. 


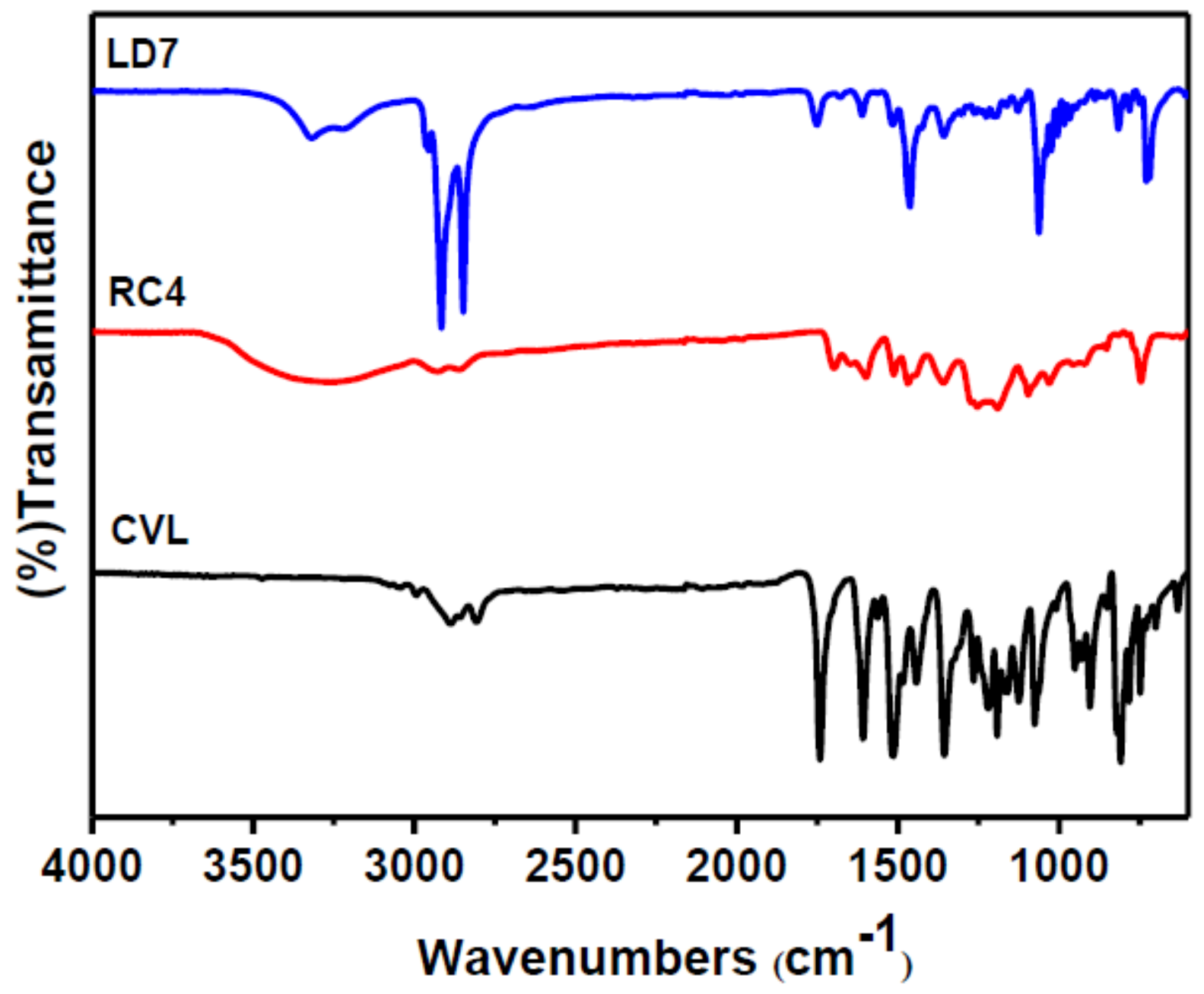

Figure 3

ATR-FTIR spectra of CVL, RC4 and LD7.

a)

b)
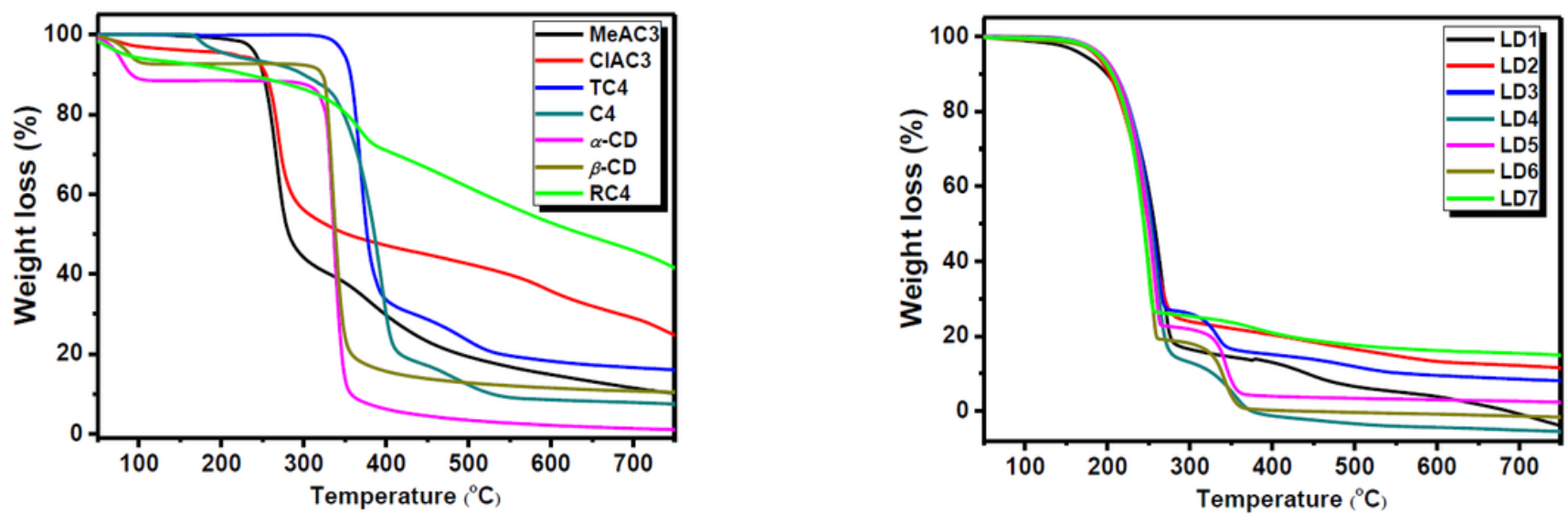

Figure 4 
TGA curves of macrocyclic compounds (a) and LD1-LD7 (b).

a)

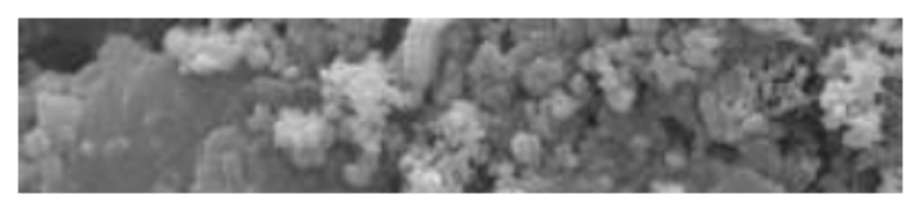

b)

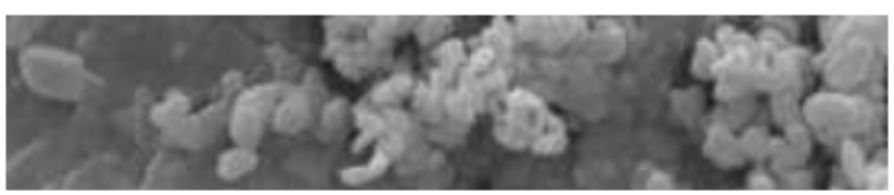

\section{Figure 5}

SEM: $500 x(a), 10,000 x(b)$, leuco pigments with average diameters of $0.3-0.6 \mathrm{~mm}$ that were developed with BPA. $500 x(\mathrm{c}), 10,000 \times(\mathrm{d})$ and leuco pigments with average diameters of 2.8-3.5 $\mathrm{mm}$ that were developed with RC4. 

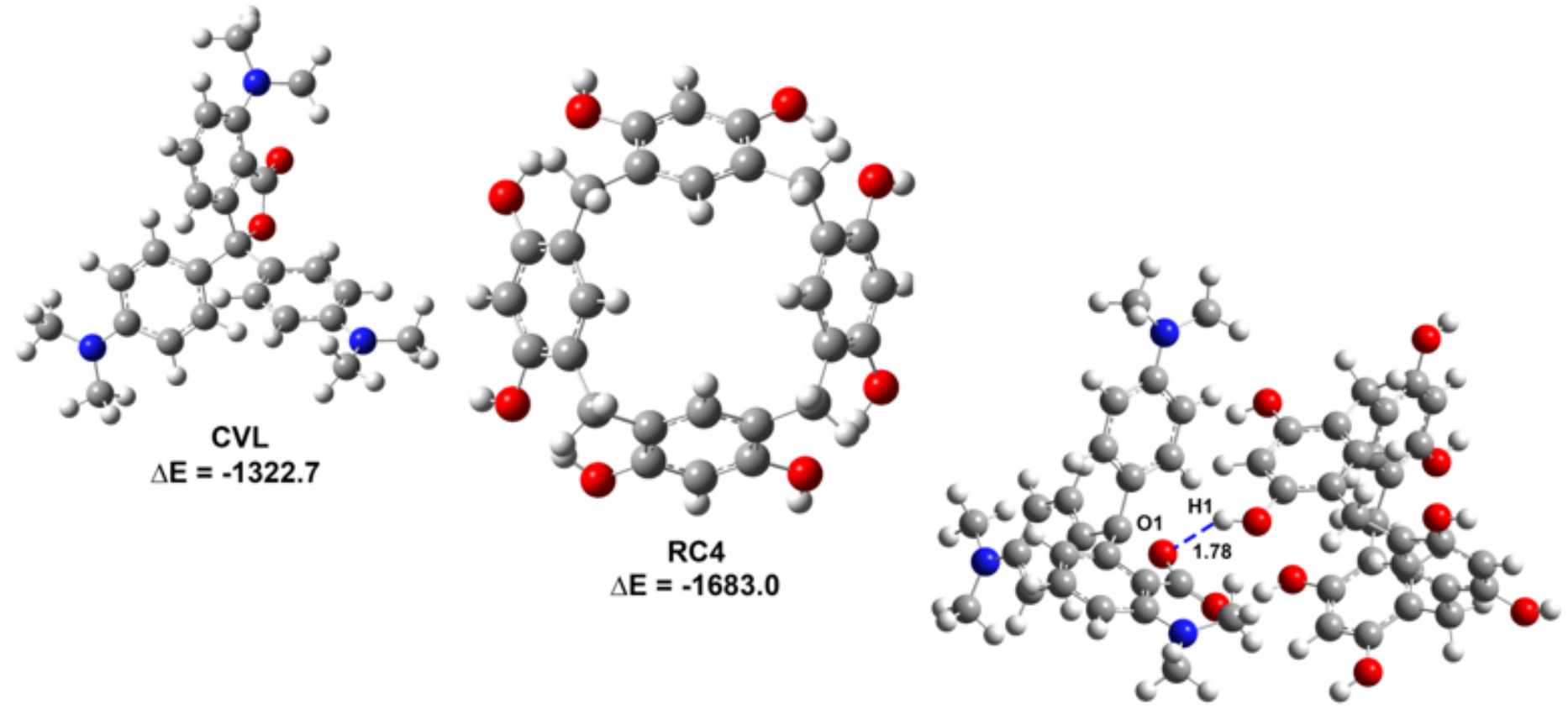

$\Delta E=-3005.7$

Figure 6

The optimized structures of CVL, RC4 and LD7, obtained at a B3LYP/LanL2DZ level of theory with the lowest energy structures in a.u.. 


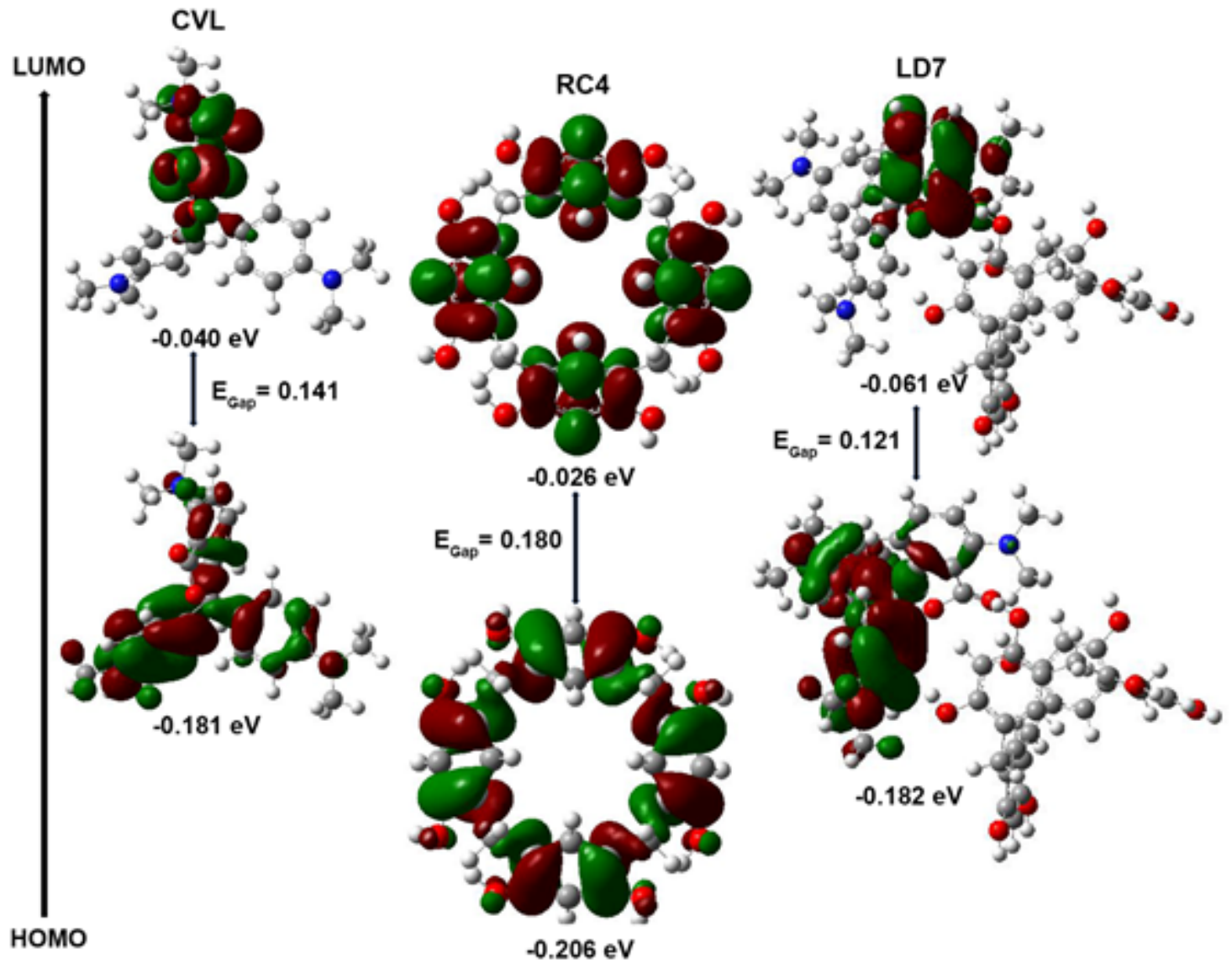

Figure 7

Molecular orbital diagrams and calculated HOMO-LUMO energy levels of CVL, RC4 and LD7. 


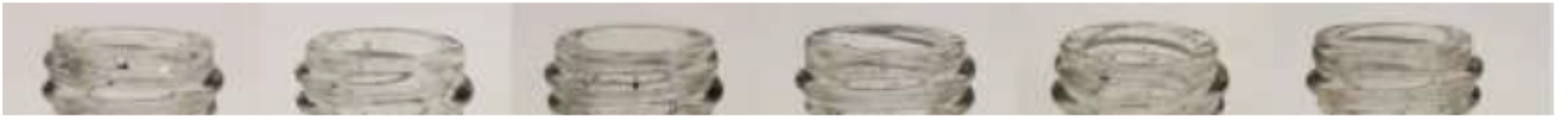

\section{Figure 8}

Photographs of $\mathbf{L D 7}$ at various temperatures $\left(30-80^{\circ} \mathrm{C}\right)$ (up) and graph of color differences in LD7 as a result of heating and cooling processes (down).

\section{Supplementary Files}


This is a list of supplementary files associated with this preprint. Click to download.

- 03CKGraphicabstract.doc 